(14) Hungria - Comentários - pág. 10.

15) H. Donnedieu de Vabres - Traité de Droit Criminel et de Legislation Penale Comparee - Paris, 1947 - pág. 53.

(16) Eugênio Florian - Op. citada - pág. 45 e e 46.

(18) Carrara - Apêndice - pág. 16.

(19) Carrara - Programa - Vol. I - pág. 4.

(20) Carrara - Programa - Vol. I - pág. 4.

(22) Carrara - Programa - Vol. I - pag. 4 .

(23) Carrara - Programa - Vol. I - pág. 41.

(24) Carrara - Programa - Vol. I - pág. $48 / 49$.

(25) Carrara - Programa - Vol. I - pág. 49.

(26) Carrara - Programa - Vol. VII - pág. 162.

(27) Carrara - Programa - Vol. I - pág. 61.

(28) Carrara - Programa - Vol. I - pág. 67.

(29) Carrara - Programa - Vol. I - Prefácio - pág. XV.

(31) Carrara - Programa - Vol. I - Prefácio - pág. XV.

(32) Carrara - Programa - Vol. I - pág. 5.

(33) Henrique Ferri - Princípios de Dir. Criminal - S. Paulo pág. 40.

(34) Ferri - Op. cit. - pág. 399.

(35) Ferri - Op. cit. - pág. 399

(36) Garófalo - Criminologia - Turin - Bocca, 1885 - pág. 30.

(37) Jorge F. Caballero - El Processo Ejecutivo del Delito - pág. 89

(38) Franz von Liszt - Tratado de Derecho Penal - Tomo 2. $-\mathrm{pag}$ - 89 gunda Edição - Madrid, 1927 - pág. 56

(39) F. von Liszt - Op. cit. - pág. 252 .

(40) F. von Liszt - Op. cit. - pág. 252 .

(41) F. von Liszt - Op. cit. - pág. 254

(42) F. von Liszt - Op. cit. - pág. 324

(43) F. von Liszt - Op. cit. - pág. 324.

(44) E. Florian - Op. cit. - pág. 32.

(45) Filippo Grispigni - Derecho Penal Italiano - Vol. I (1) Buenos Aires, 1948 - pág. XXX.

(46) F. Grispigni - Op. cit. - pág. XXXIX.

(47) F. Grispigni - Op. cit. - Vol. I (2) - pág. 44.

(48) F. Grispigni - Op. cit. - Idem - pág. 45.

(49) F. Grispigni - Op. cit. - Idem - pág. 45.

(50) F. Grispigni - Op. cit. - Idem - pág. 61.

(51) F. Grispigni - Op. cit. - Idem - pág. 260

(52) Jimenez de Asua - El Criminalista - tomo $20^{\circ}$ - pág. 30

(53) Beling - "Die Lehre vom Verbrechem" - 1906

(54) J. de Asua - Op. cit. - pág. 32.

(55) J. de Asua - Op. cit. - pág. 33

56) E. Florian - Op. cit. - pág. 382

(57) Sebastián Soler - Anais da Primeira Conferência Pan-Americana de Criminologia - Imprensa Nacional, 1948 - "Estrutura Jur|dica del Crimen" - pág. 171.

(58) S. Soler Op. cit. - pág. 173.

(59) S. Soler Op. cit. - pág. 174.

(60) S. Soler Op. cit. - pág. 175.

(62) Victor Cathrein, S. J. - Filosofia del Derecho - Madrid, 1945 pág. 54 .

\section{FUNÇÃO ECONÔMICA DO TRANSPORTE *}

\section{Mem de Sá}

Transporte é o deslocamento material dos bens no espaço.

Assim, sendo a circulação dos bens, em Economia, definida como a passagem dêles do produtor ao consumidor, o transporte em amplíssima margem se confunde com o fenômeno da circulação, pois que, via de regra, esta implica aquêle. Daí, costumar-se distinguir, nos compêndios, dois conceitos de circulação: o econômico, próprio, amplo, e o restrito. No primeiro, circulação é a passagem ou transmissão de direitos sôbre os bens, entendendo-se que êles circulam quando mudam de proprietário. A distinção tem pleno cabimento quando se pensa na hipótese de transmissão de bens imóveis e, particularmente, quando se refere às operações correntes nas Bôlsas e nos chamados Armazéns Gerais. Em todos êstes, a circulação se opera independentemente de transporte. Mas, abstraídos que sejam, na prática e na realidade corrente da vida econômica, transporte se confunde com circulação ou, mais precisamente, não se pode verificar esta última sem a ocorrência do primeiro. Teríamos, assim, em forma muito genérica, expressa a função primacial do transporte.

Remontando a períodos recuados da vida econômica e social, bem é de ver que, então, a confusão ou implicação aludida teria sido a norma.

Em tais períodos foi o transporte por terra, usando da fôrça humana ou da animal, o que primeiro se praticou. Era o transporte terrestre entre tribos e clãs, entre agricultores e artesãos, entre os produtores do campo e os dos primeiros agrupamentos na vila.

Desde que a evolução econômica chegou ao surgimento do comércio como ato específico de intermediação, com a característica de habitualidade e de profissão, natural é que o transporte se haja igualmente desenvolvido; mais preciso, talvez, fôra dizer que o desenvolvimento do transporte é que permitiu a eclosão daquela atividade. $\mathrm{E}$, nesta fase, via de regra a função comercial se confundiu com a transportadora. O transportador era o comerciante. Nesta fase, cuja *) Prova escrita do concurso prestado recentemente pelo autor para provimento da
cátedra de Economia Política, sôbre ponto sorteado na ocasião. 
duração se projeta por muitos séculos e que assume predominância até o século 19, é que se desenvolve, em seus inícios, o transporte por água, rios ou mares interiores, muito principalmente o Mediterrâneo.

Desde a descoberta da roda - cuja importância para a civilização dispensa seja ressaltada - e desde a descoberta do aproveitamento da fôrça do vento para o transporte por água, durante largas centúrias não se registram progressos nos processos de transporte, isto é, com mais precisão, nos três elementos básicos que o integram: a via, o. veículo e o motor.

Em fins do século 18 e começos do 19, coincidindo com a chamada "revolução industrial", ou melhor, dela fazendo parte integrante e saliente, ocorrem sucessivamente invenções e revelações técnicas que se prolongam ao longo do último século. Elas ocorrem nos três elementos citados, e, de forma mais acentuada, no que concerne ao motor. São tais inventos e seus resultados, a aplicação prática que a vida econômica lhes deu, que permitiram revelar-se, em tôda a extensão e alcance, a função econômica do transporte.

Não interessa ao ponto em exposição determo-nos na significação particular de cada um de tais inventos, conhecidos e constantemente referidos: o motor a vapor, o motor a explosão interna com a utilização do petróleo em suas diversas formas, o tratamento da via terrestre pelo processo de Mac-Adam, a ferrovia, o avião, a fôrça elétrica - eis, aí, sem ordem lógica nem cronológica, os que mais profundamente puderam revelar a capacidade e a amplidão das funções transportadoras.

Tambem foge ao ponto ressaltar as funções sociais, culturais e políticas exercidas pelo transporte, mediante o contrato, o conhecimento e a interpenetração recíproca dos povos, dos hábitos, costumes e gráus diversos de civilização, que o transporte possibilitou. Ressaltemos apenas que todos êstes aspectos se entrelaçam estreitamente à função estritamente econômica do transporte e, na maioria dos casos, decorre dela; isto é, foi o exercício da função econômica do transporte que geralmente permitiu, propiciou e desenvolveu os demais aspectos. Nem seria demais deixar a anotação de que o transporte, como condição essencial do comércio, esteve muito de perto ligado à política e às relações internacionais.

Mas, retornando ao fio da exposição, devemos acentuar que foi com o adiantamento dos meios de transporte - e ainda graças à descoberta da bússola - que a civilização se alargou e o homem veio a tomar posse ou pelo menos conhecimento do seu orbe.

Com os grandes descobrimentos e, depois, com os progressos técnicos dos secs. 18 e 19 , desdobram-se os horizontes da vida econômica e no decurso dos séculos 16 a 19 ocorre uma profunda e radical modificação na própria estrutura econômica dos povos. Foge também, à exposição, mostrar as causas múltiplas desta mudança de estrutura - causas múltiplas e complexas, sem dúvida, mas, entre as quais, bem se deve destacar a do transporte como das de ação mais efe iva.

Chegados, entretanto, a êste gráu de evolução e de progresso, atingido $o$ imenso desenvolvimento dos transportes que caracteriza o século 19 e, muito especialmente, a primeira metade do atual podemos alinhar as mais destacadas funções que o transporte exerceu ou tem possibilidade de exercer:

- Reconhecida a importância fundamental da divisão do trabalho, como fenômeno básico de todo progresso material do homem, bem é de ver que o transporte o complementa essencialmente, pois sem êle a divisão do trabalho entre os homens teria ficado apenas embrionária, sem condições de promover a eclosão de seus frutos.

$\mathrm{E}$, dentre as formas de divisão do trabalho, de forma particular tudo deve à função transportadora a que tem sido denominado divisão internacional ou, melhor, territorial do trabalho.

E' baseado na excelência desta virtude do transporte, que a corrente livre cambista alicerçou sua admirável construção teórica. A divisão territorial do trabalho, graças ao transporte, permite aos homens o aproveitamento ideal dos recursos naturais de que dispóem ou, usando da linguagem da escola matemática, permite a ofelimidade máxima. Ela - divisão, - com o transporte, realizaria entre as regiões e as nações o aproveitamento ótimo dos recursos, consoante os princípios das escolas liberal e hedonística - o maior rendimento com o menor dispêndio. Possibilitaria o aproveitamento de tais recursos mediante a' especialização das atividades humanas. Daí, a bela teoria dos custos comparativos que asseguraria a todos os povos, indistintamente, gozar de tais vantagens, ainda quando fôssem os menos bem dotados de condições ou recursos naturais. Não analisaremos, entretanto, a procedência ou realidade dêsses argumentos - (Benini resumiu o ponto de vista hoje dominante dizendo que se trata de uma "bela ilusão teórica") - nem os demais do velho debate entre livre câmbio e protecionismo.

Mas, inegável é, como balanço da contenda, que o ideal do melhor aproveitamento do trabalho e dos recursos naturais - que se realize êle integralmente ou apenas com as drásticas restrições e extremas reservas dos dias atuais - inegável é que ao transporte - em mas reservas dos dias atuais - inegave econômica primacial - se deve tudo quanto temos e ainda gozamos da divisão territorial do trabalho, vigente, aliás, plenamente quando se exerce sem peias políticas e alfandegárias, entre partes ou regiões de um mesmo país.

- Conseqüência direta desta primeira, e de máximo destaque para a economia, é a função do transporte como ampliador ilimitado dos mercados. Temos aqui uma das causas fundamentais da alteração de estrutura que marca a evolução econômica dos fins da Idade Média para a época moderna. Caracterizava, entre outras marcas não menos 
importantes, aquela economia o fato da limitação do mercado. E, daí, a par do desfavor natural, the decorreram méritos assinalados por todos os estudiosos. Era o período da produção para o aconsumo, isto é, para as necessidades efetivas da coletividade, ao invés do traço marcante da economia moderna: produzir para produzir lucro, atendendo e esperando necessidades de mercados distantes e ilimitados; o consumidor não mais comanda a produção, mas é comandado por ela. Como diria Marx, ao ciclo mercadoria-dinheiro-mercadoria, substituise o ciclo dinheiro-mercadoria-dinheiro.

Foi, portanto, o transporte que permitiu a expansão onímoda e quase sem limites dos grandes centros produtores que, por meio dêle, esperam colocar seus produtos em mercados mundiais. Não há que distinguir, nestas concepções, entre necessidades humanas essenciais ou simples satisfação suntuária de prazer ou de confôrto.

- Em decorrência da função anterior, outra surge: o transporte ou criou ou possibilitou as grandes concentrações urbanas modernas. Certo que outras existiram em épocas distantes da história. Mas as atuais são, por via de regra, consequiência direta da criação da grande indústria e do grande comércio, graças à existência de grandes mercados, que, de sua vez, são fruto da função transportadora. Anote-se; doutra parte, que, criado o grande centro produtor, criado está o grande centro consumidor.

Vamos aí encontrar o transporte - que, aliás, é condição essencial para a existência do grande centro urbano, pois a função do transporte interno, dentro dêle, é imprescindível para a sua vigência - vamos aí encontrar o transporte, dizíamos, como causa de um dos fenômenos de maior transcendência na vida econômica e social da era moderna. Tôda a questão chamada social - isto é, tôda a questão das relações entre trabalho e capital, tôda a luta que caracteriza a civilização ocidental, nos últimos séculos, de concorrência de extermínio, de concentrações econômicas, de luta de classes, de consciência de direitos e reivindicações, de iniqüidades sociais no critério da distribuição das riquezas - tudo isto deriva, em grande parte, da criação dos grandes centros urbanos e das grandes concentrações humanas e proletárias.

- Afora estas, de maior relevância, e ainda como decorrências delas, outras se assinalam ao transporte. Assim, a da possibilidade ou tendência para a igualização de preços entre os diversos mercados. Tal tendência ou possibilidade, cuja significação é evidente, é, entretanto, relativa. Ela deflui do extraordináric progresso do transporte e de sua conseqüente degressão de custo. Vigora, ou poderia vigorar, porém, para certas classes de mercadorias, aquelas que têm o atributo da densidade econômica, isto é, em que é favorável a relação entre valor e pêso ou volume. Assim, não existissem barreiras protecionistas, para grande número de bens, graças ao transporte barato dos dias atuais, poderiam as nações gozar de preços sensivelmente iguais para artigos da mesma espécie e qualidade.
- Ainda outra: o melhor aproveitamento das mercadorias perecíveis. Estas, que são em grande número, e interessam diretamente, em geral, à subsistência do homem, graças ao transporte, podem ser servidas a consumidores distantes, máxime com o aparecimento dos transportes em câmaras frigoríficas, possibilitando, mais uma vez, o aumento da produção de certos bens e o aumento de bem-estar à humanidade.

Expostas, em linhas gerais, e a vol-d'oiseau, as funções principais do transporte, devemos nos deter na forma específica pela qual estas funções se distribuem entre os diversos tipos ou sistemas de transporte. Podem ser êstes assim classificados, para o que interessam ao ponto:

Por terra: ferroviários ou rodoviários.

Por água: fluviais (incluindo lacustres) e marítimos.

Por ar: aviação.

Os requisitos que se reclamam dos transportes, por sua vez, são: segurança, rapidez, regularidade, comodidade e barateza.

São os interêsses da produção, da circulação e consumo dos bens que, em cada caso, determinarão a eșcolha do tipo ou sistema mais adequado ao preenchimento da função transportadora.

Bem é de ver que todos os sistemas são, do mesmo passo, ou em determinado gráu, concorrentes e complementares entre si.

$\bar{E}$ assim, em boa parte, função do transporte rodoviário, e, em menor gráu do fluvial, alimentar o transporte ferroviário. Êste, bem como os dois outros, fornece cargas ao transporte marítimo e ao áereo, como os dois outros, fornece cargas a dicar os pontos de contato e conjugação entre êles, sendo função de cada um, até certo ponto, alimentar os demais.

Doutra parte, porém, é a concorrência que prevalece entre êles na disputa da função. E é o interessado no transporte quem vai de cidir pela preferência, de acôrdo com a significação que, em cada cidir pela preferencia, de acôrutos ou requisitos acima enumerados Em outras palavras, o interessado, em cada caso, procurará a "linha de menor resistência" econômica ao escolher o tipo de transporte. de menor resistenciacer, em linhas gerais e pouco rígidas, a função predominante de cada tipo na realização da função genérica do transporte.

Para facilidade de exposição, tomemos como base ou ponto dt referência, o transporte ferroviário que tem sido, e ainda continua ser, em geral, dos de maior vulto de carga dentro de cada país.

O transporte ferroviário reúne uma série de caracteres de que decorrem conseqüências diretas quer para a sua preferência, ques para os efeitos da concorrência com os demais. 
Dêstes característicos, o primacial é o de ser um sistema que exige a inversão de grandes, senão imensos capitais fixos. Assim, temos o caso de emprêsas em que, para o cálculo do custo unitário, é a parte chamada constante que largamente prevalece.

São, efetivamente, capitais fixos, criadores de quotas de custc constante, nas emprêsas ferroviárias: a chamada linha, ou via, permanente, ou leito de transporte; todos os elementos de tração e de circulação (máquinas e vagões); assim como constantes são as despesas de administração e as chamadas despesas gerais; as de reparação e reconstituição (oficinas, etc.) e, ainda, em grande parte, a de pessoal.

Acresce que dentre os atributos do t. ferroviário estão os da regularidade e segurança - o que significa, de acôrdo com o primeiro, quє as emprêsas devem fazer circular composições regulares dentro $\mathrm{d} \epsilon$ horários e entre pontos determinados, afora os que, não sujeitos a tais determinações, se formam de acôrdo com a procura de transporte.

Em qualquer caso, porém, em geral, formada uma composiçãc ferroviária, a parte variável das despesas, integrantes do custo, é relativamente pequena em relação à constante: consiste principalmente em combustíveis, lubrificantes e, em muito pequena escala, em pessoal.

Há ainda a levar em conta que o caso do transporte, especialmente do ferroviário, é um caso característico de emprêsa de produção de produtos conjuntos; como chama a teoria econômica; isto é, dentro do têrmo geral de transporte e carga, há uma multiplicidade de tipos que, por analogia, se assimilam ao caso padrão dos produtos conjuntos. Esta mesma analogia leva a designar como um caso símile ao do subproduto o que se chama, em transporte, frete de retôrno.

Das linhas sumàriamente descritás, depreende-se que se torna pràticamente inexeqüível ligar em cada caso o preço do transporte (frete) ao seu custo.

A noção de custo: tonelada-quilômetro, passageiro-quilômetro é teòricamente obtida e o custo unitário teòricamente calculado. Mas, pràticamente, não é possível fixá-lo com precisão ex-ante (para usar uma expressão cara aos economistas suecos), mas apenas ex-post.

Daí o fato de serem as tarifas ferroviárias traçadas em bases estatísticas e obedecerem à norma de fixação do custo dos produtos conjuntos, isto é, estipulam-se tarifas diversas, obedecendo a critérios múltiplos, de forma a que as receitas globais cubram as despesas globais, ou de forma a que, das tarifas, a média ponderada dos fretes se aproxime ou ultrapasse da média do custo unitário.

Usando de outra forma, pode-se afirmar que não existe relação de fixidez entre cada tarifa ou frete e o seu respectivo custo, havendo uma larga margem para acomodações que têm por critério, afinal, o custo médio unitário.

Inferências dêstes princípios fàcilmente se percebem. A primeira delas é que a distância é fator de significação menos importante na ferrovia do que, p. ex, no veículo rodoviário. A ferrovia, em outros têrmos, opera francamente em consonância com o princípio do custo decrescente. Assim, em geral, suas tarifas, em conseqüência, são degressivas, isto é, o frete da tonelada- $\mathrm{Km}$. diminui com a distância, porque a economia ferroviária assim o favorece.

Outra conseqüência está na possibilidade de fretes de retôrno que fiquem abaixo do custo médio, ou mesmo que apenas cubram a parte variável, também chamada especial, do cüsto unitário (o retôrno opera como subproduto). Esta circunstância possibilita a dualidade de tarifas conforme a direção do transporte e, em conséqüência, outorga à ferrovia, com especialidade, uma notável função: a de estímulo de zonas econômicamente pouco produtoras.

Esta falta de fixidez na relação entre frete e custo, ainda se distingue, na elaboração das tarifas, permitindo que algumas delas atendam ao critério do valor do produto, em conexão com sua capacidade de sofrer maior ônus (o que depende, de sua vez, do gráu de elasticidade da procura do bem em causa). Daí, novas combinações se oferecem: o frete de algumas, por lucrativo, permite o frete abaixo de custo (ou apenas cobrindo o custo variável) de outras mercadorias. Permite, ainda, tal série de combinações, o estabelecimento de tarifas especiais, preferenciais, de combate, etc. em que a emprêsa tem em vista as características econômicas das zonas servidas e a concorrência de outros tipos de transporte.

Mas, do conjunto de tais elementos, chega-se, em resumo, à afir mativa de que o tr. ferroviário tem preferência sôbre o rodoviário para as cargas de menor densidade econômica e para as grandes distâncias. Sua função econômica é, pois, primordial, pois sem elas difìcilmente teriam escoamento os artigos mais baratos (principalmente gêneros alimentícios) e ficariam sem ligação com os grandes centros consumidores as zonas de produção mais distante. Isto encareceria ou dificul dores as zobres, e daria maiores possibilidades tàs "rendas de situação", isto é, enriqueceria os produtores próximos, a coberto da concorrência dos distantes.

Se, do ferroviário, passarmos ao rodoviário, pondo-os em confronto - e vamos nos referir exclusivamente ao de veículos automotores, por motivos óbvios - especialmente depois do extraordinário surto da técnica registrada principalmente neste século, quer quanto

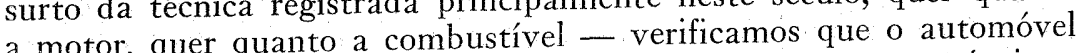
cifere profundamente do trem, não só quanto a aspectos técnicos, cifere profundame são mas tambem exclusivamente correm a cargo das emprêsas as despesas da bastante menores (nariáveis: combustíveis, lubrificantes, pneus salários (sendo de notar que êstes são relativamente muito pneus, salarios (sendo unitário no tr. rodoviário do que no ferroviário). mais onerosos ao custo unitário no tr. rodoviario do que no ferroviário).

Em resultado, não se vêrifica a degressão dos custơs, o
a 
Em compensação, porém, o automóvêl ơferece uma série de vantagens sôbre o seu concorrente, especialmente a adaptação à carga, isto é, a consideração às exigências específicas das mercadorias, a extrema mobilidade, a ausência de rigidez do traçado, o fato de estar à disposição a qualquer momento, e, sobretudo, o fato de permitir o transporte de porta a porta, como se costuma dizer. Ora, esta circunstância redunda na economia dos transbordos, que tanto onera o tr. ferroviário.

Doutra parte, a concorrência entre as emprêsas transportadoras geralmente não permite a discriminação de tarifas conforme o valor da carga. Daí, pela concorrência, haver a tendência de coincidir o frete com o custo unitário, ressalvadas, naturalmente, as hipóteses de rendas.

Em conclusão, o transporte rodoviário vence para as distâncias pequenas, em geral calculadas até $200 \mathrm{kms}$., e para as mercadorias de maior densidade econômica.

Doutra parte, a extrema mobilidade, a possibilidade de rotas diversas e de paradas a qualquer momento, (os "atalhos", etc.) dão outra função econômica à rodovia: ela fecunda e estimula mais enèrgicamente o progresso de uma região do que a ferrovia. Emquanto esta opera aquêle estímulo originando núcleos e povoações distanciadas umas das outras (as "estações" e "paradas" que são os pontos de concentração de carga das zonas influídas) o automóvel dissemina a produção e o incremento econômico com mais uniformidade ao longo de todo o leito e nas regiões adjacentes.

Passando ao transporte fluvial, encontramos nêle características que lhe permitem um custo unitário de transporte muito mais baixo do que os demais. A via natural de que se serve é a primeira grande vantagem, pois ainda nos casos de regularização de rios, de construção de eclusas ou canais, tais obras não correm por conta das emprêsas e permitem longos prazos de amortização. Acresce o fato de serem igualmente de pequeno desgate, e, pois, de longa amortização, o capital fixo das emprêsas (embarcações em geral) e, ainda, o da feliz relação entre pêso bruto e capacidade de carga - isto é, relação econômica de transporte entre a carga total, inclusive combustivel, e a capacidade de carga útil - muito favorável. No transporte por água, quer fluvial, quer marítimo, aliás, outro ponto merece destaque: suas despesas são pràticamente constantes, esteja o veículo em marcha ou estacionado, pois, quando em marcha, apenas as despesas de combustível (que são das mais baixas em relação ao efeito) é que acrescem. Portanto, quer no transporte fluvial, como no marítimo, a distância exerce mínima importância; o que importa é a existência de carga abundante, de ida e retôrno, qualquer que seja a quilometragem.

Mas, na fluviovia há a desvantagem da fixidez das linhas, que dependem dos próprios cursos tais como os traçou a natureza, ou,

dentro de estreitos limites, de obras de engenharia, unindo tais cursos através de canais.

Graças, porém, às vantagens acima expostas, o tr. fluvial exerce insuperável concorrência aos terrestres, a pequenas ou longas distâncias, para as mercadorias de menor densidade econômica e que não exijam rapidez. Não esqueçamos, porém, como já referido, que as ferrovias, em determinadas hipóteses, podem enfrentar vantajosamente a concorrência, mediante fretes abaixo de custo, como lhe permitem as características de suas tarifas. As emprêsas de navegação fluvial freqüentemente operam sem tarifas fixas, mas através de combinação prévia de frete em cada caso, e devem, em linhas gerais, acomodar seu frete ao custo unitário. Como as ferrovias, porém, e graças à regularidade de suas linhas, tem a possibilidade de fretes de retôrno vantajosos e baratos.

Uma função especial da via fluvial é a localização ao pé de suas margens, e nas zonas portuárias, de um determinado grupo de indústrias - tôdas as que carecem de transporte barato, dada a natureza do produto ou matéria-prima. De outra parte, ela permite esta localização, como dissemos, ao longo de todo o curso, o que favorece a desconcentração ou disseminação da indústria, o progresso de amplas regiões, etc.

Fácil se torna, por oposição, fixar, em poucas linhas, as características do tr. aéreo que, nas últimaś décadas, tem tido um desenvolvimento dificilmente previsível. Êste é, de todos, o mais rápido. Mas, doutra parte, o de maior custo, dadas as altas despesas variáveis: grande despesa de combustíveis, grande desgaste de materiais, grandes salários com pessoal altamente especializado. Também não são pequenas as despesas constantes com o que se chama a infraestrutura dos serviços, as oficinas de reparação e o vulto das inversões em capitais fixos. Daí, em conseqüência, o transp. aeroviário estar em condiçóes especiais em relação aos outros: êstes the são alimentadores de carga e pouca influência exercem, quanto à concorrência, dado que a aerovia é usada apenas para carga de alta densidade econômica e que exige especial rapidez, pois esta é o atributo por excelência do avião.

Ouanto ao transporte marítimo, sua função é específica: a ligacão de continentes e regiôes, através de mares e oceanos. Os transportes por terra e os fluviais são alimentadores de sua carga e em poucas situacões lhe podem fazer concorrência (apenas entre países ou zonas vizinhos, servidos por boas linhas férreas ou rodoviárias). Mesmo nesta situação, o transporte marítimo leva vantagem quanto a fretes, que são muito menores do que os terrestres por motivos que foram direta ou indiretamente expostos. Doutra parte ou encarando doutro prisma, o transporte marítimo é complementar aos demais, pois leva ao destino transoceânico a carga trazida ao pôrto pelos outros tipos transportadores. 
De todo o exposto, podem ser fixadas conclusões.

Dentro da função genérica do transporte, cada tipo tem sua função específica. Embora concorram entre si, em muitos casos, são complementares uns dos outros e podem e devem, por isto, ser coordenados, para proveito geral da economia nacional, como da universal.

A ferrovia, o transporte marítimo e o aéreo oferecem grande regularidade, enquanto o rodoviário é o que menor índice de regularidade apresenta. Quanto a velocidade, depois do avião, a ferrovia é a de maior índice, máxime nas longas distâncias (basta pensar que o automóvel é forçado a parar longas horas por dia) e o transporte fluvial o de menor gráu.

Quanto à comodidade, o automóvel a todos supera pelas suas características de adaptação e mobilidade. Quanto a custo: o avião, o automóvel para longas distâncias, o trem para pequenas, o transporte fluvial e o marítimo se apresentam em ordem decrescente.

Fácil será depreender as inúmeras combinações possíveis entre êstes vários sistemas - o que não tem faltado de se verificar, quer espontâneamente, por entendimentos (cartéis, ententes, etc.), entre êles, quer sob a iniciativa do Poder Público. Cremos, aliás, que êste é um dos setores em que mais se verifica - e progressivamente ocorre a intervenção do Estado na Economia, sob inúmeras modalidades.

E' que a função econômica do transporte aparece como fundamental e exerce influência decisiva sôbre todos os setores e aspectos da vida econômica. As características de muitos dos sistemas estudados, particularmente o ferroviário, o marítimo e o aéreo, conduzem naturalmente à concentração, fato quase universalmente observado. Isto fàcilmente se explica porque quanto maiores as zonas atendidas, quanto mais variados seus produtos, maiores vantagens se oferecem ao transporte, em sua economia interna e na elaboração de suas tarifas. Mostramos, doutra parte, que, principalmente no tr. ferroviário, domina a característicà da pluralidade de fretes, isto é, a multiplicidade de preços em categorias (o que se observa também no transporte de pessoas) - e êste é um traço específico dos preços de monopólio. Daí, portanto, por diversos motivos de ordem econômica, se haver chegado às mais altas formas de concentração e de cartelização ou trustificação nos vários gêneros de transporte.

Sempre que isto ocorre, natural e necessária é a intervenção do Poder Público, em qualquer das múltiplas formas que se registram, atualmente, nos vários países do mundo, para a defesa da economia e dos interêsses da coletividade, para a proteção do bem comum, em uma palavra.

E nada melhor do que isto sublinha a transcendência da função econômica do transporte.

\section{OS IMÓVEIS SITUADOS NO URUGUAI E A EXTRATERRITORIALIDADE DO ESTATUTO BRASILEIRO REFERENTE AO REGIME DE BENS NO CASAMENTO}

Camillo Martins Costa

\section{EXPOSIÇÃO}

Marido e mulher brasileiros, casados, no Brasil, na vigência do Código Civil, sem contrato antenupcial, querem, agora, desquitar-se. Casamento se realizou antes de 1942. Ambos os nubentes eram doO casamento se realizou antes rém se fixou o domínio conjugal. Não ocorreu qualquer dos motivos indicados no $\$$ único do art. ${ }^{\circ} 258$ do Código Civil como determinantes do regime de separação obrigatória. Antes do casamento, o marido adquirira, por herança materna, um imóvel situado na República do Uruguai. Pretende êle que tal imóvel representa patrimônio seu, particular, isto é, não compreendido no patrimônio do casal, e que, assim, na partilha, referente ao projetado desquite, não entrará o aludido imóvel. Posto isso,

\section{PERGUNTA-SE:}

$10^{\circ}$ E ou não o regime da comunhão universal de bens que prevalece nesse casamento?

$2^{\circ}$ ) No caso afirmativo, - êsse imóvel do Uruguai estará, porventura, excluído da comunhão?

3. ${ }^{\circ}$ Se o imóvel não está excluído na comunhão, haverá, para a mulher, alguma dificuldade no sentido de tornar efetivo o seu direito de incluí-lo na partilha?

$\left.4 .^{\circ}\right)$ No caso de existir alguma dificuldade a êsse respeito de que modo se poderia proceder para obviá-la? 